\title{
Digital Nudging for Online Social Sharing: Evidence from A Randomized Field Experiment
}

\author{
Ni Huang \\ Arizona State University \\ ni.huang@asu.edu \\ Yili Hong \\ Arizona State University \\ hong@asu.edu
}

\author{
Pei-yu Chen \\ Arizona State University \\ peiyu.chen@asu.edu \\ Shin-yi Wu \\ Arizona State University \\ shinyi.wu@asu.edu
}

\begin{abstract}
This study investigates the effectiveness of digital nudging for users' social sharing of online platform content. In collaboration with a leading career and education online platform, we conducted a large-scale randomized experiment of digital nudging using website popups. Grounding on the Social Capital Theory and the individual motivation mechanism, we proposed and tested four kinds of nudging messages: simple request, monetary incentive, relational capital, and cognitive capital. We find that nudging messages with monetary incentive, relational and cognitive capital framings lead to increase in social sharing behavior, while nudging message with simple request decreases social sharing, comparing to the control group without nudging. This study contributes to the prior research on digital nudging by providing causal evidence of effective nudging for online social sharing behavior. The findings of this study also provide valuable guidelines for the optimal design of online platforms to effectively nudge/encourage social sharing in practice.
\end{abstract}

\section{Introduction}

Online social sharing refers to the phenomenon that the users of an online platform share content from the platform to their social media connections [23]. The purpose of online social sharing is to have users spread word-of-mouth (WOM) about a platform, such that the platform benefits from the increased impressions and potential adoptions in the users' online social networks [6]. Social sharing is at the heart of online customer acquisition as user-shared WOM carries more credibility among potential users than firm-generated WOM [17, 24]. Managers consider social sharing the most effective use of social media [3]. It is estimated that about $94 \%$ of online retailers have been practicing social sharing, and more than $68 \%$ of the millennial social media users in the U.S. report somewhat likely influence of their social media friends' posts on their purchase decisions [15].

Despite its importance, social sharing does not come easily to online businesses. With few exceptions (e.g., social sharing of news articles and pro-social initiatives), users are oftentimes reluctant to share WOM about businesses for several reasons. To begin with, some users do not bother to social share as there is inherited social risk in doing so [14]. Additionally, others might be concerned about their online privacy, and thus are less likely to social share $[13,18]$. Further, some might become wary of their social images when it comes to share commercial information to its social networks.

This study seeks to improve our understanding on how to effectively nudge for online social sharing. Prior research in this space has been focusing on why individuals social share [37], what content are likely to be shared [6], and who intend to share [26]. However, little effort has been made to understand how we can optimally nudge users so that they are willing to share the website or application services to their friends on social networking platforms. We aim to fill this knowledge gap in the literature.

Meanwhile, common industry practice on social sharing mainly involves in the integration of online platforms with social media, hoping that the users voluntarily share information about the platforms in their social networks [20]. For instance, a platform can add the Facebook Share button to its webpages, which supports users share the platform's content on their Facebook timeline or to their social connections via Facebook messages [29]. Alternatively, a few companies have started to explicitly ask users to share their website, application, or shopping experience to their friends, examples of which include Amazon.com, 
Kohl's.com, Sears.com, etc. While the effectiveness of these existing approaches remains to be tested, we rarely observe companies implement nudging for social sharing. Thus, by conducting a randomized field experiment on how to effectively nudge for online social sharing, the findings of our study would provide immediate and valuable guidelines for industry practitioners.

Grounding on the Social Capital Theory and the individual motivation mechanism, this study proposes four hypotheses/treatment groups, namely simple request, monetary incentive, relational capital, and cognitive capital. To test our hypotheses, we conducted a large-scale randomized field experiment in collaboration with a leading career and education online platform in China, hereafter referred to as Company I. Specifically, we created website popups displaying the four treatment messages that are designed to nudge users to share the platform's content to their social networks. Our results show that nudging users by providing monetary incentive, as well as emphasizing relational and cognitive capital significantly increase the likelihood of users to social share the platform's content. Interestingly, we also find that simply requesting users to social share would backfire on the platform, leading to less sharing. The findings of our study suggest that simply requesting users to social share would be unwise for online platforms. It is important to accompany messages with either monetary incentive or social capital framings (i.e., relational capital and cognitive capital) when nudging users for social sharing.

The rest of the paper is organized as follows. First, we briefly summarize the related literature. Second, building on the theoretical arguments, we propose the hypotheses of this study. Third, we will dive into the study context and the experimental design of our randomized field experiment. We then present the data, analysis, and main findings of our study. Lastly, this paper concludes with discussions on the theoretical and managerial implications of our findings, limitations of the present study, as well as opportunities for future research.

\section{Related Literature}

\subsection{Digital Nudging}

Digital nudging involves in using computer-user interface design components to influence online users' behavior or choices [38]. Different from traditional nudging, which has been used to influence individual behaviors in a variety of offline scenarios such as organ donation [21], political voting [16], and energy saving [4], digital nudging mainly occurs in the online environment [30]. With the development of the Internet, digital nudging has become a growing research stream. For example, Acquisti (2009) proposed that digital nudging can be used to influence individuals' online privacy revelation behaviors. Another example is that digital nudging has been shown to effectively help people make more costeffective choices when selecting healthcare plans [22].

This study contributes to the research on digital nudging by improving our understanding on how to use digital nudging for online social sharing. Our digital nudging process follows Weinmann et al. [38] and goes as the following: defining context and objectives, theorizing ideas and treatments, selecting nudging approaches, and implementing the experiment. Moreover, our nudging approaches fit into the nudging mechanisms of activating a desired behavior by incentivizing and encouraging individuals [28, 35]. Although prior research has explored the use of digital nudging for offline social interactions [1], not much work has investigated the potential impact of nudging on online social sharing behavior. Meanwhile, prior work on online social sharing has been focusing on the motivations behind sharing [37], the attributes of the shared content [6], and the characteristics of individuals who are likely to share [26]. There is a lack of understanding on how to effectively nudge users for social sharing. Our work aims to fill this void of research on both digital nudging and online social sharing.

\subsection{Social Capital Theory}

The Social Capital Theory suggests that the set of recourses inherited in social network relationships as social capital significantly influence the extent of social actions [7, 27, 31] According to the social structure perspective of the theory, there are three types of social capital: structural capital (the network connections among actors), relational capital (the interrelationships among actors), and cognitive capital (the shared information among actors) [31]. The Social Capital Theory was traditionally proposed to understand the interpersonal interactions within a society and organizations [31, 32]. With the establishment of information technology that affords networking infrastructure and the formation of social capital [9], recent work has employed this theory to explain the knowledge contributing and sharing behavior in electronic networks and virtual communities [10,37]. Our study extends the Social Capital Theory into the context of online social sharing in online platforms. Specifically, we design the nudging/treatment messages based on the idea of motivating social sharing by pointing out the potential 
development in relational capital or cognitive capital when users social share.

\section{Hypotheses Development}

A nudge with a simple request framed message is a website initiated solicitation of sharing of its services. There are two reasons a simple request (e.g., in the form of a pop up message) may work. First, as the literature has repeatedly shown, the "power of asking" is quite substantial. For example, in an experiment involving allocation of $\$ 10$ between a subject and a receiver, Andreoni and Rao [5] show that anytime a receiver asks, the giving increases from the subject, and it largely works through empathy. Similarly, Yörük [39] used a propensity score matching approach to find that the effect of personal solicitation on the propensity to volunteer is considerable. This leads us to believe that a simple request nudging may exhibit a similar effect of "power of asking," such that the users may be more willing to share than no nudging at all (organic sharing). Second, when a user benefits from the website's content, the user may have tendencies to reciprocate to the website by accepting the request to sharing its services in social media, which would amplify the effect of request, because without the nudge, the user may not take extra efforts to find the sharing button and spread the word of mouth.

There are also clear downsides with a simple request, versus not requesting at all. One key difference between this context of online content sharing with solicitation of charity or volunteering is that users are typically involved in a browsing task, and the digital nudging may interrupt the users' flow [12], and thus create a bad user experience. And this bad user experience may create user annoyance, which may hinder users who would otherwise organically spread word of mouth from doing so.

While we believe, there are both positive and negative sides to the effect of a simple request nudging on users' sharing behavior, overall, we would expect to see a net positive effect. Hereby, we formally propose the following:

H1. Nudging with a simple request framed message has a significant positive effect on user social sharing behavior, comparing to no nudging at all.

Traditional economic theory holds that individuals are rational and utility-driven [33,34]. Consequently, monetary incentive should be an effective approach in motivating desired behaviors. With few exceptions [17], majority of the previous research has shown that monetary incentive can effectively change people's offline behavior. For instance, monetary incentive is directly linked to individual effort and task performance [7], and financial incentive can increase the likelihood of smokers quit smoking [36]. The significant influence of monetary incentive on user behavior also extends to the online environment. For example, Hong et al. [19] show that monetary incentive can motivate users to send social referrals. Burtch et al. [8] find that financial incentives effectively induce users to contribute online reviews. In the same vein as prior work, we expect that monetary incentive would lead to increases in users' social sharing behavior. Therefore, we hypothesize that:

H2. Nudging with a monetary incentive framed message has a significant positive effect on user social sharing behavior, comparing to no nudging at all.

As predicted by the Social Capital Theory, the expectation of forming relational capital or cognitive capital could motivate social affairs [9]. The relational capital refers to the inter-relationships among actors in a social network [31]. Coleman [11] pointed out that relational capital facilitates actions that benefit the members in the network. The relational capital happens when individuals are willing to help others [25]. On the other hand, the cognitive capital involves the shared information among actors [31]. The development of cognitive capital relies on the sharing of knowledge [37]. Thus, we expect that when nudging users with emphasis on the potential development of relational capital or cognitive capital, users are more likely to share. In particular, nudging that emphasizes social sharing being helpful to friends is associated with relational capital, while nudging that emphasizes letting friends know your interests is related to cognitive capital. Formally, we hypothesize the following:

H3a. Nudging with a relational capital framed message has a significant positive effect on user social sharing behavior, comparing to no nudging at all.

H3b. Nudging with a cognitive capital framed message has a significant positive effect on user social sharing behavior, comparing to no nudging at all.

\section{Experimental Design}

Our large-scale randomized field experiment was conducted in collaboration with a leading career and education online platform in China (Company I). This online platform mainly hosts information about university descriptions, college major introductions, and career choices and path outlook. With the support 
of the company's CEO and CTO, we conducted our experiment for a period of four and half months in 2017. Our randomized field experiment serves as an $\mathrm{A} / \mathrm{B}$ testing of digital nudging for social sharing for the Marketing and Product Team of the corporate partner.

We randomized unique incoming visits to the website's universities descriptions section, and as a result, the randomization of our experiment was realized at the web traffic level. When a website visitor browses a page, after a random amount of time $(>15$ seconds), the visitor will be assigned into one of the five groups in our experimental design. Table 1 presents the five groups in our experiment.

Table 1. Experimental Groups

\begin{tabular}{cll}
\hline Group & $\begin{array}{l}\text { Treatment } \\
\text { Control group } \\
\text { (no popup) }\end{array}$ & Message Framing \\
\hline 2 & Simple request & $\begin{array}{l}\text { Share this webpage with } \\
\text { your friends! }\end{array}$ \\
\hline 3 & $\begin{array}{l}\text { Monetary } \\
\text { incentive }\end{array}$ & $\begin{array}{l}\text { Share this webpage with } \\
\text { your friends! You will } \\
\text { receive a free } \\
\text { subscription service from } \\
\text { Company I! }\end{array}$ \\
\hline 4 & Relational & $\begin{array}{l}\text { Share this webpage with } \\
\text { your friends! They may } \\
\text { capital the information } \\
\text { helpful! }\end{array}$ \\
\hline 5 & $\begin{array}{l}\text { Cognitive } \\
\text { capital }\end{array}$ & $\begin{array}{l}\text { Share this webpage with } \\
\text { your friends! Let your } \\
\text { friends know your } \\
\text { interests in the } \\
\text { information! }\end{array}$ \\
& &
\end{tabular}

Notes: The messages were shown to the users in in Chinese, not in English.

The first group is our control group, wherein the visitors will not receive any popup at all. This group represents the organic social sharing by platform users. The second group is the treatment group with simple request message framing, in which the visitors will receive a popup in the format of a message box floating in the middle of the web page, nudging the visitor to share the web page with their friends through social media. The third group is the monetary incentive group, wherein the visitors will receive a popup that asks the visitor to share the webpage with their friends through social media in exchange for a free subscription service from the Company I. The fourth group is the treatment group with relational capital message framing, wherein the visitors will receive a popup suggesting that their social media friends may find the webpage useful or relevant. The fifth group is the cognitive capital messaging framing group, wherein the visitors will receive a popup, reminding them to share the webpage with their friends and show their interests in the information.

Figure 1 shows an exemplary popup that was prompted to platform visitors on a webpage. Figure 2a presents the typical webpage display without a popup, while Figure $2 b$ presents the webpage with a popup.



Figure 1. Exemplary Webpage Popup for Group 2 (Share this webpage with your friends!)

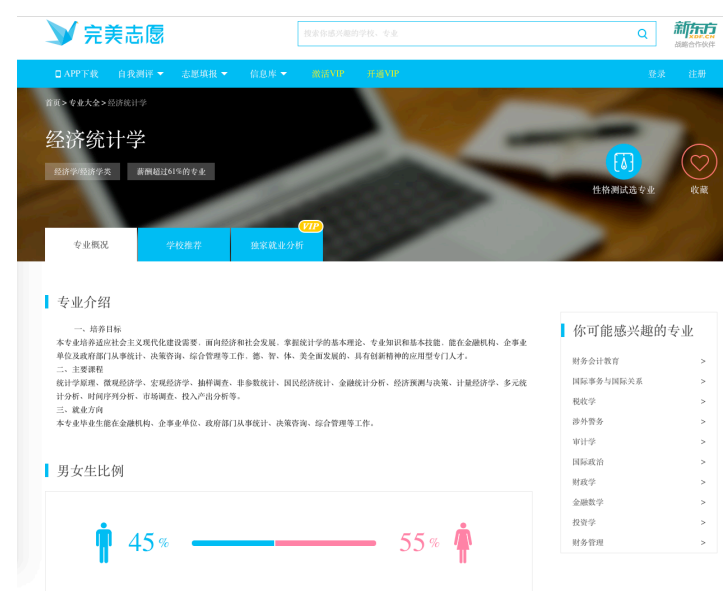

Figure 2a. Webpage Display without Popup

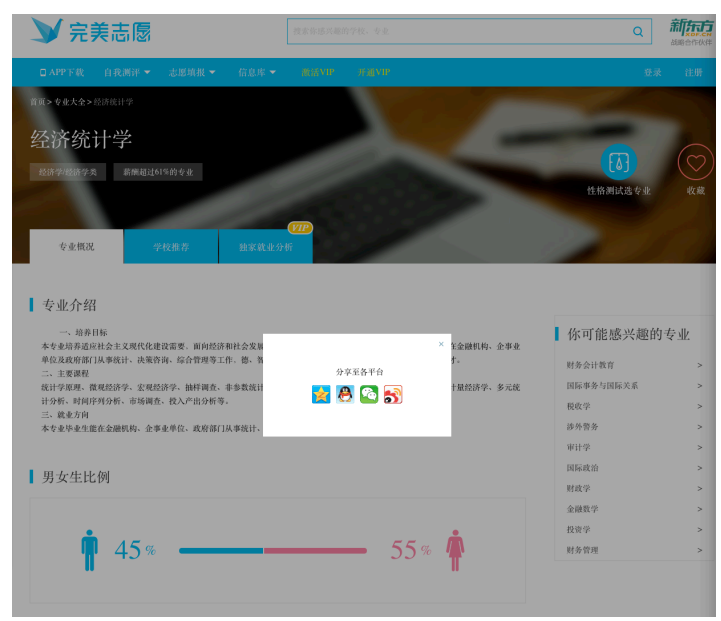

Figure 2b. Webpage Display with Popup

(The four boxes in the popup represent the different social media channels) 
During the experiment, the corporate partner captures data on which experimental group the visitor was randomized to, whether and when the popup was initiated/displayed, whether the webpage visitor clicked to share, and to which social media platform the visitor shared. We then combine the data on users' experimental assignment and sharing behavior to examine which treatment group is more effective in nudging users for social sharing.

\section{Data \& Analysis}

\subsection{Descriptive Statistics}

Our randomized field experiment has received a total of 45,206 unique visits during the experimental period (from January 1 to May 15, 2017), producing each group with approximately 9,000 observations. We observe that, the average sharing rate across five groups is $2.70 \%$, which is much higher than the organic sharing rate of our control group (no popup at all) being at $1.85 \%$. In addition, the monetary incentive group shows the highest sharing rate $(3.95 \%)$ which is more than double the sharing rate of the control group. The group with the second highest sharing rate $(3.12 \%)$ is the one with the cognitive capital framing, "Share this webpage with your friends! Let your friends know your interests in the information!" Meanwhile, the treatment group with the third highest sharing rate $(2.99 \%)$ is the group with the relational capital message framing, "Share this webpage with your friends! They may find the information helpful!" Interestingly, the treatment group with the least effective nudging is the simple request group, having a social sharing rate of $1.50 \%$, which is surprisingly worse than our control group. Table 2 reports the descriptive statistics for the social sharing data per group.

Table 2. Descriptive Statistics

\begin{tabular}{lcccc}
\hline Group & Share & $\begin{array}{l}\text { Not } \\
\text { Share }\end{array}$ & Total & $\begin{array}{l}\text { Sharing } \\
\text { Rate }\end{array}$ \\
\hline $\begin{array}{l}\text { Control } \\
\text { group }\end{array}$ & 163 & 8,633 & 8,796 & $1.85 \%$ \\
\hline $\begin{array}{l}\text { Simple } \\
\text { request }\end{array}$ & 134 & 8,793 & 8,927 & $1.50 \%$ \\
\hline $\begin{array}{l}\text { Monetary } \\
\text { incentive }\end{array}$ & 361 & 8,775 & 9,136 & $3.95 \%$ \\
\hline $\begin{array}{l}\text { Relational } \\
\text { capital }\end{array}$ & 272 & 8,815 & 9,087 & $2.99 \%$ \\
\hline $\begin{array}{l}\text { Cognitive } \\
\text { capital }\end{array}$ & 289 & 8,971 & 9,260 & $3.12 \%$ \\
\hline Total & 1,219 & 43,987 & 45,206 & $2.70 \%$ \\
\hline
\end{tabular}

We also visualize the sharing rates across the experimental groups in Figure 3. As shown below, the monetary incentive group seems to be the most effective nudging approach in terms of boosting sharing rate, followed by the cognitive capital group and the relational capital group. Quite interestingly, simply requesting users to share the web page with their social media friends is the least effective way to nudge online social sharing. In fact, it turns out to have adverse effect on sharing rate comparing to the control group of no popups at all.

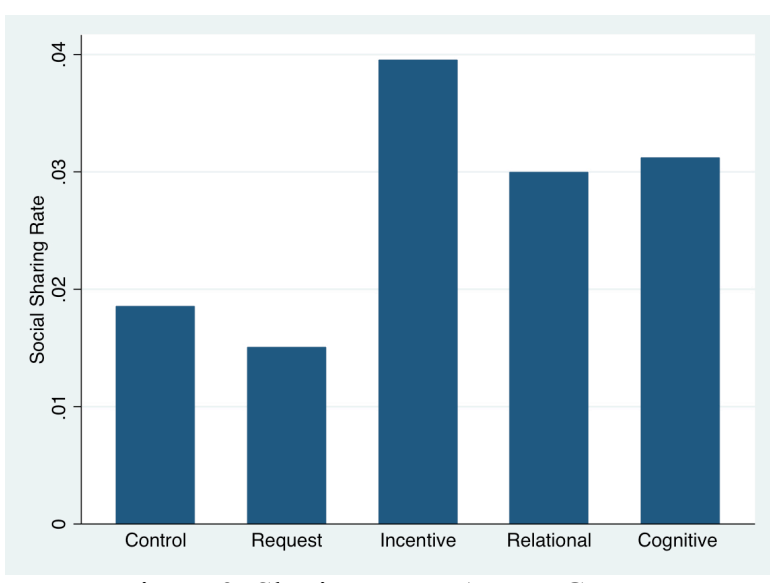

Figure 3. Sharing Rates Across Groups

\subsection{Mean Comparisons}

To estimate the statistical significance of the differences in sharing rates across experimental groups, we conduct mean comparisons of sharing rates for each group using $t$-tests. The results of the $t$-tests show that, comparing to the users in the control group (no popup), those in the monetary incentive group (Diff. $=0.021, p$ $<0.01$ ), relational capital (Diff. $=0.011, p<0.01$ ) and cognitive capital (Diff. $=0.013, p<0.01$ ) framing groups show significantly higher rates of social sharing behavior. Moreover, it appears that the monetary incentive group is more effective in nudging for social sharing than other treatment groups. Meanwhile, the difference in sharing rates between the relational and the cognitive capital group is statistically insignificant (Diff. $=0.001, p>0.10)$, suggesting that the relational capital framing and the cognitive capital framing can be used as alternatives for nudging for social sharing. Table 3 presents our results on mean comparisons across experimental groups. 
Table 3. Mean Comparisons

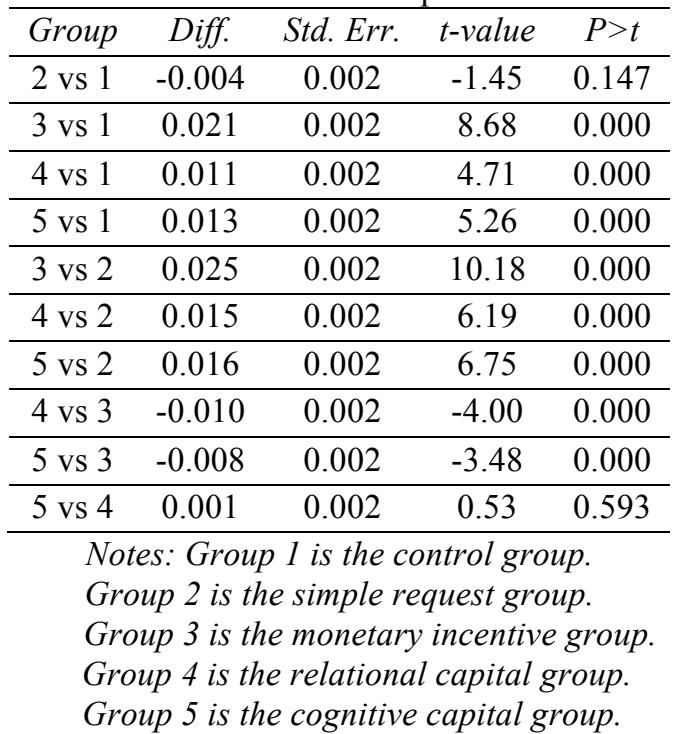

\subsection{Regression Analysis}

We further conducted regression analysis with date fixed effect to control for the date of the visits. Specifically, we estimated the following equation:

Social_share ${ }_{i t}$

$$
\begin{aligned}
& =\beta_{0}+\beta_{1}{ }^{*} \text { Simple_request }_{i t} \\
& +\beta_{2}{ }^{*} \text { Monetary_incentive } \\
& +\beta_{3}{ }^{*} \text { Relational_capital }_{i t} \\
& +\beta_{4}{ }^{*} \text { Cognitive_capital }_{i t} \\
& +\sum T_{t}+\varepsilon_{i t}
\end{aligned}
$$

In the above equation, $i$ indexes the platform visitors, and $t$ denotes the dates of the visit.

We estimated both a linear probability model (LPM) and a logistic model without and with date fixed effects using a vector of date dummies. Also, we used clusterrobust standard error clustered at the date level for the LPM. Table 4 reports the LPM regression results, and Table 5 presents the logistic estimation results. Based on the delta method calculations of the LPM model, compared with the control group (no pop-up request), the simple request group achieves $20.5 \%$ less user sharing, the monetary incentive group increase user sharing by $31.3 \%$, relational capital group and cognitive capital group respectively accrues $21 \%$ and $16.7 \%$ more user sharing. Consistent with our findings from the mean comparisons, both the LPM and logistic regression results show that nudging users with monetary incentive appears to be the most effective approach for social sharing, supporting $\mathrm{H} 2$. Additionally, in support of $\mathrm{H} 3 \mathrm{a}$ and $\mathrm{H} 3 \mathrm{~b}$, using nudging messages with relational capital framing or cognitive capital framing lead to significant increase in social sharing behavior as well. However, in contrast to $\mathrm{H} 1$, simply requesting users to social share appears to

\begin{tabular}{|c|c|c|}
\hline & (1) & (2) \\
\hline$D V:$ & Social Share & Social Share \\
\hline Simple request & $\begin{array}{l}\mathbf{- 0 . 0 0 3 5 *} \\
(0.0019)\end{array}$ & $\begin{array}{l}\mathbf{- 0 . 0 0 4 5 * * *} \\
(0.00124)\end{array}$ \\
\hline Monetary incentive & $\begin{array}{l}\mathbf{0 . 0 2 1 0 * * *} \\
(0.0025)\end{array}$ & $\begin{array}{l}\mathbf{0 . 0 0 8 8} * * * \\
(0.00192)\end{array}$ \\
\hline Relational capital & $\begin{array}{l}\mathbf{0 . 0 1 1 4} * * * \\
(0.0023)\end{array}$ & $\begin{array}{l}\mathbf{0 . 0 0 5 6} * * * \\
(0.00188)\end{array}$ \\
\hline Cognitive capital & $\begin{array}{l}\mathbf{0 . 0 1 2 7 * * *} \\
(0.0023)\end{array}$ & $\begin{array}{l}\mathbf{0 . 0 0 4 4} * * \\
(0.0019)\end{array}$ \\
\hline Constant & $\begin{array}{l}0.0185 * * * \\
(0.0014)\end{array}$ & $\begin{array}{l}0.0240 * * * \\
(0.0010)\end{array}$ \\
\hline Observations & 45,206 & 45,206 \\
\hline $\mathrm{F} / \mathrm{Chi}^{2}$ & $37.02 * * *$ & $20.47 * * *$ \\
\hline Date FE & No & Yes \\
\hline Number of date & -- & 116 \\
\hline
\end{tabular}
have backfire on the online platform, resulting in significantly less sharing behavior than the organic

\begin{tabular}{|c|c|c|}
\hline \multirow[b]{2}{*}{$D V:$} & (1) & (2) \\
\hline & Social Share & Social Share \\
\hline \multirow{2}{*}{ Simple request } & $-0.214 *$ & $-0.500 * * *$ \\
\hline & $(0.118)$ & $(0.160)$ \\
\hline \multirow[t]{2}{*}{ Monetary incentive } & $0.779 * * *$ & $0.599 * * *$ \\
\hline & $(0.096)$ & $(0.127)$ \\
\hline \multirow{2}{*}{ Relational capital } & $0.491 * * *$ & $0.417 * * *$ \\
\hline & $(0.100)$ & $(0.131)$ \\
\hline \multirow[t]{2}{*}{ Cognitive capital } & $0.534 * * *$ & $0.337 * *$ \\
\hline & $(0.099)$ & $(0.132)$ \\
\hline \multirow[t]{2}{*}{ Constant } & $-3.970 * * *$ & \\
\hline & $(0.079)$ & \\
\hline Observations & 45,206 & 44,848 \\
\hline $\mathrm{F} / \mathrm{Chi}^{2}$ & $141.56 * * *$ & $75.62 * * *$ \\
\hline Date FE & No & Yes \\
\hline Number of date & -- & 70 \\
\hline
\end{tabular}
social sharing in the control group.

Table 4. LPM Regression Analyses

Table 5. Logistic Regression Analyses

Page 1488 


\section{Discussions}

\subsection{Key Findings}

How to effectively nudge users for social sharing? Partnering with a leading online education and career information platform in China, we conducted a largescale randomized field experiment to answer this important question. Three interesting findings emerge from our experiment. First, it appears that nudging visitors to social share by a simple request is even worse than not asking at all. Second, perhaps not quite surprising, monetary incentive is highly effective at nudging users to do social sharing. The third finding is that using relational capital message or cognitive capital message are both significantly effective at nudging users for social sharing, compared with the control group without nudging. Notably, since nudging with relational capital or cognitive capital framed messages is essentially cost free, they could be excellent alternatives to the monetary incentive approach.

\subsection{Implications}

This study makes several unique contributions to academic research. First, our work contributes to the nascent research stream on digital nudging. Answering the call for future research on digital nudging proposed by Weinmann et al. [38], this study advances our understanding on the optimal design of information artifacts that helps online platforms encourage user social sharing. Second, to the research stream on social sharing, this study makes a pioneering effort in conducting a randomized field experiment and showing causal evidence on the effectiveness and counter-effectiveness of different nudging approaches for online social sharing. Lastly, this study contributes to the Social Capital Theory by extending this theory into the online social sharing context.

Our study also offers important managerial implications. With the development of the web technologies, many websites have gone beyond relying on organic user sharing of WOM to their friends, and have been starting to experiment on digital nudging. Our study shows that digital nudging should properly align with users' motivation for content sharing, and, if designed inappropriately (e.g., simple request with a pop up window in our experiment), it may backfire, achieving results even worse than not nudging users. We surmise that this could be due to an annoying interruption of users' page browsing, which creates a bad user experience. On the other hand, we find three digital nudging strategies that are relatively effective. Online platform managers could use a monetary incentive to increase user's social sharing. This approach of using extrinsic motivation has seen quite some success in other contexts, and one obvious drawback is that the website needs to invest in the incentive, and a return on investment analysis may be needed for such a strategy. Alternatively, website managers could use digital nudging with framings that relate to users' relational capital or cognitive capital, which may effectively motivate users to share contents without expending the monetary incentives. The relational capital and cognitive capital nudging proves to significantly increase users' social sharing than either simply request or not nudging at all.

\subsection{Limitations \& Future Research}

There are several limitations to this study, which also offer ample opportunities for future research. One limitation is that our randomized field experiment was conducted in China, thus our results can be mainly generalized to the Chinese population. However, since Chinese market is huge by itself, the impact of our study is still substantial. Yet, it will be interesting to examine if the findings of this study also hold true in other cultures/societies. Future research may replicate our study in another market of different culture. Additionally, it would be fruitful to quantify the financial value of social sharing in future research, examining the optimal quantity of monetary incentive for social sharing. Another potential future research is to consider the long-term impact of the nudging interventions. For example, as we can expect, the value of the incentive will also play an important role at the effectiveness of social sharing. Meanwhile, as a tradeoff, providing monetary incentive could be an additional cost to the website's operation. Future work needs to investigate whether and how the monetary give-away pays off in the long run. In fact, we have planned to collaborate with our corporate partner to obtain subsequent data on those visitors who shared on social media in exchange of monetary rewards: whether they come back to the website, and their visit frequency. Furthermore, this study did not test the heterogeneous treatment effects based on the users' characteristics. For instance, it is possible that the effectiveness of different digital nudging for social sharing is more salient for male users than for female users, or vice versa. Understanding how the effects of nudging on the users' social sharing behaviors would vary for different user types can be a fruitful direction for future research. 


\section{References}

[1] A. Abouzied, and J. Chen. "CommonTies: A Contextaware Nudge Towards Social Interaction", Proceedings of the Companion Publication of the 17th ACM Conference on Computer Supported Cooperative Work \& Social Computing. ACM, 2014.

[2] A. Acquisti, "Nudging privacy: The behavioral economics of personal information", IEEE security \& privacy, 7(6), 2009.

[3] Adobe, "2013 Digital Marketing Optimization Survey Results", April 26, 2013, Retrieve from http://www.mycustomer.com/sites/default/files/attachments/ Adobe-32060_2013_optimization_survey_results_UE.pdf

[4] H. Allcott, "Social norms and energy conservation", Journal of Public Economics, 95(9), 2011, pp. 1082-1095.

[5] J. Andreoni, and J.M. Rao, "The Power of Asking: How Communication Affects Selfishness, Empathy, and Altruism", Journal of Public Economics, 95(7), 2011, pp. 513-520.

[6] J. Berger, and E.M. Schwartz, "What Drives Immediate and Ongoing Word of Mouth?", Journal of Marketing Research, 48(5), 2011, pp. 869-880.

[7] S.E. Bonner, and B.S. Geoffrey, "The Effects of Monetary Incentives on Effort and Task Performance: Theories, Evidence, and A Framework for Research", Accounting, Organizations and Society, 27(4), 2002, pp. 303-345.

[8] G. Burtch, Y. Hong, R. Bapna, and V. Griskevicius, "Stimulating Online Reviews by Combining Financial Incentives and Social Norms", Management Science, 2017, forthcoming.

[9] A. Calabrese, and M. Borchert, "Prospects for Electronic Democracy in the United States: Rethinking Communications and Social Policy", Media, Culture, and Society, 18, 1996, pp. 249-268.

[10] C.M. Chiu, M.H. Hsu, and E.T. Wang. "Understanding Knowledge Sharing in Virtual Communities: An Integration of Social Capital and Social Cognitive Theories", Decision Support Systems, 42(3), 2006, pp. 1872-1888.

[11] Coleman, J., Foundations of Social Theory, Cambridge, Mass.: Belknap Press, 1993.

[12] Csikszentmihalyi, M., Finding Flow: The Psychology of Engagement with Everyday Life, Basic Books, 1997.

[13] C. Dwyer, S. Hiltz, and K. Passerini, "Trust and Privacy Concern within Social Networking Sites: A Comparison of Facebook and MySpace", AMCIS 2007 Proceedings, 2007, p. 339.
[14] A.B. Eisingerich, H. Chun, Y. Liu, H. Jia, and S.J. Bell, "Why Recommend a Brand Face-to-face But not on Facebook? How Word-of-mouth on Online Social Sites Differs from Traditional Word-of-mouth", Journal of Consumer Psychology, 25(1), 2015, pp. 120-128.

[15] EMarketer, "Social Commerce Roundup", July 2014, Retrieved from http://www.emarketer.com/public_media/ docs/emarketer_social_commerce_roundup.pdf

[16] A.S. Gerber, P.G. Donald, and W. L. Christopher, "Social Pressure and Voter Turnout: Evidence from A Largescale Field Experiment", American Political Science Review, 102(01), 2008, pp. 33-48.

[17] U. Gneezy, and A. Rustichini, "Pay Enough or Don't Pay at All", The Quarterly Journal of Economics, 115(3), 2000, pp. 791-810.

[18] R. Gross, and A. Acquisti, "Information Revelation and Privacy in Online Social Networks", In Proceedings of the 2005 ACM Workshop on Privacy in the Electronic Society, pp. 71-80.

[19] Y. Hong, P.A. Pavlou, K. Wang, and N. Shi, "On the Role of Fairness and Social Distance in Designing Effective Social Referral Systems", MIS Quarterly, 2017, forthcoming.

[20] N. Huang, Y. Hong, and G. Burtch, "Social Network Integration and User Content Generation: Evidence from Natural Experiments", MIS Quarterly, 2017, forthcoming.

[21] E.J. Johnson, and G. Daniel, "Do Defaults Save Lives?", Science, 302(5649), 2003, pp. 1338-1339.

[22] E. J. Johnson, R. Hassin, T. Baker, A.T. Bajger, and G. Treuer, "Can Consumers Make Affordable Care Affordable? The Value of Choice Architecture", PloS One, 8(12), 2013.

[23] A.M. Kaplan, and H. Michael, "Users of the World, Unite! The Challenges and Opportunities of Social Media", Business Horizons, 53(1), 2010, pp. 59-68.

[24] V. Kumar, and R. Mirchandani, "Increasing the ROI of Social Media Marketing", MIT Sloan Management Review, 54(1), 2012, p. 55.

[25] C.R. Leana, and H. J. Van Buren, "Organizational Social Capital and Employment Practices," Academy of Management Review, 24(3), 1999, pp. 538-555.

[26] F. Li, and T. C. Du, "Who is Talking? An Ontologybased Opinion Leader Identification Framework for Wordof-mouth Marketing in Online Social Blogs", Decision Support Systems, 51(1), 2011, pp. 190-197.

[27] Lin, N., K.S. Cook, and R.S. Burt, (Eds.), Social Capital: Theory and Research, Transaction Publishers, 2001. 
[28] K. Ly, N. Mazar, M. Zhao, and D. Soman, "A Practitioner's Guide to Nudging", Research Report Series Behavioural Economics in Action, Rotman School of Management, Toronto, 2013, pp. 1-28.

[29] A. Malhotra, C. K. Malhotra, and A. See, "How to Create Brand Engagement on Facebook", MIT Sloan Management Review, 54(2), 2013, p. 18.

[30] T. Mirsch, C. Lehrer, and R. Jung, "Digital Nudging: Altering User Behavior in Digital Environments", 2017, Retrieved from: https:/wi2017.ch/images/wi2017-0370.pdf

[31] J. Nahapiet, and S. Ghoshal, "Social Capital, Intellectual Capital, and the Organizational Advantage", Academy of Management Review, 23(2), 1998, pp. 242-266.

[32] R. D. Putnam, "The Prosperous Community", The American Prospect, 4(13), 1993, pp. 35-42.

[33] H.A. Simon, "A Behavioral Model of Rational Choice", The Quarterly Journal of Economics, 69(1), 1955, pp. 99-118.
[34] H.A. Simon, "Economic Rationality: Adaptive Artifice", The Sciences of the Artificial, MIT Press, Cambridge Mass., 1981.

[35] Thaler, R.H., and C.R. Sunstein, Nudge: Improving Decisions About Health, Wealth, and Happiness, Yale University Press, New Haven, 2008.

[36] K.G. Volpp, A.B. Troxel, M.V. Pauly, H.A. Glick, A. Puig, D.A. Asch, and E. Corbett, "A randomized, Controlled Trial of Financial Incentives for Smoking Cessation", New England Journal of Medicine, 360(7), 2009, pp. 699-709.

[37] M.Mc. Wasko, and F. Samer, "Why Should I share? Examining Social Capital and Knowledge Contribution in Electronic Networks of Practice", MIS Quarterly, 2005, pp. 35-57.

[38] M. Weinmann, C. Schneider, and J. vom Brocke, "Digital Nudging", Business \& Information Systems Engineering, 58(6), 2016, pp. 433-436.

[39] B.K. Yörük, "The Power of Asking in Volunteering: Evidence from a Matched Sample", Economics Letters, 99(1), 2008, pp. 79-84. 